\title{
Human Prescription Drug Manufacturing
}

National Cancer Institute

\section{Source}

National Cancer Institute. Human Prescription Drug Manufacturing. NCI Thesaurus.

Code C106643.

The process of manufacturing prescription medications for humans by a pharmaceutical company. 